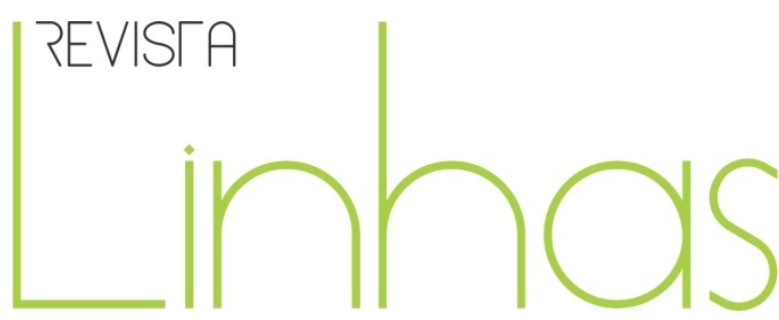

\title{
Breve estudo sobre a relação entre família e escolarização para os batistas - Belo Horizonte/MG, década de 1920
}

\begin{abstract}
Resumo
A partir da metade do século XIX, chegavam ao Brasil missionários protestantes interessados em estabelecer sua fé e princípios sociais neste país. Buscando alcançar este objetivo, a educação escolar foi uma das principais estratégias eleitas pelos missionários. Este trabalho trata acerca de uma instituição escolar protestante específica, o Collegio Baptista Americano Mineiro, fundado em 1918 em Belo Horizonte, Minas Gerais. Através de fontes disponíveis no arquivo da instituição, buscou-se identificar as representações acerca das famílias brasileiras feitas pelos missionários educadores batistas.
\end{abstract}

\author{
Taciana Brasil dos Santos \\ Mestre em Educação pela \\ Universidade Federal de Minas \\ Gerais - UFMG - Brasil \\ tacianabrasil@yahoo.com.br
}

Palavras-chave: Famílias; Educação escolar; Igreja batista.

\section{Para citar este artigo:}

SANTOS, Taciana Brasil dos. Breve estudo sobre a relação entre família e escolarização para os batistas Belo Horizonte/MG, década de 1920. Revista Linhas. Florianópolis, v. 16, n. 30, p. 29 - 48, jan./abr. 2015.

DOI: $10.5965 / 1984723816302015029$

http://dx.doi.org/10.5965/1984723816302015029 


\title{
Brief study on the relationship between family and schooling for the Baptist - Belo Horizonte/MG,
} 1920

\begin{abstract}
From the mid-nineteenth century, Protestant missionaries arrived in Brazil interested in establishing their faith and social principles in this country. Aiming to reach this goal, schooling was one of the key strategies chosen by the missionaries. This work is about a specific Protestant educational institution, the Collegio Americano Miner Baptist, founded in 1918 in Belo Horizonte, Minas Gerais. Through available on other file sources, we sought to identify the representations concerning the Brazilian families made by the Baptist missionary educators.
\end{abstract}

Keywords: Family; Education; Baptist church. 
A partir do final do século XIX chegava ao Brasil o protestantismo chamado de missão. Através do envio de missionários, homens e mulheres, diversas denominações protestantes norte-americanas realizaram trabalho proselitista neste país. Este trabalho, porém, ia além da disseminação de princípios religiosos, estendendo-se à americanização dos modos de vida do brasileiro, tanto na esfera pública quanto privada (MENDONÇA e VELASQUES FILHO, 2002).

De acordo com Vieira (1990), foram justamente os princípios relacionados à esfera pública e política que possibilitaram a inserção e estadia dos protestantes no Brasil. Seus princípios capitalistas, progressistas, liberais e republicanos agradavam parte da elite dirigente do país, que permitiram a presença dos missionários e o desenvolvimento de seu trabalho - principalmente o educacional - como forma de trazer progresso, modernizar e civilizar o Brasil e os brasileiros.

Ribeiro (1980), porém, aponta para outra possibilidade de interpretação da inserção do protestantismo neste país. O autor defende que os brasileiros que se tornaram protestantes não foram obrigados a isso, mas o fizeram de livre vontade. A falta de comunicação entre a Santa Sé e a Igreja Católica brasileira - acentuada pelas políticas regalistas, bem como as divergências e conflitos doutrinários presentes no interior deste grupo teriam enfraquecido o catolicismo brasileiro. Após a mudança nas leis brasileiras, permitindo a entrada dos missionários e tolerando a presença de cristãos acatólicos - mesmo com essa tolerância significando a perda de diversos direitos civis, muitos brasileiros optaram por abandonar sua religião de origem, tornando-se protestantes.

As explicações de Vieira (1990) e Ribeiro (1980), embora pareçam opostas, podem ser complementares, pois explicam como o protestantismo encontrou lugar no Brasil, tanto do ponto de vista político, como do ponto de vista dos indivíduos que aceitaram mudar de religião. Para Medeiros (2010), as teorias indicam um ponto em comum: só foram possíveis devido ao progressivo enfraquecimento do catolicismo, tanto na esfera política quanto na religiosa.

Para disseminar seus princípios, os protestantes valeram-se do trabalho eclesiástico, mas também estenderam sua atuação para outras áreas. Nascimento (2007) 
descreve a ação dos presbiterianos nas áreas da educação e saúde; Mesquida (1994) descreve a atuação educacional dos metodistas; Adamovicz (2008) trata sobre a imprensa batista; Bastian (1994) descreve a atuação dos diversos grupos protestantes em várias áreas, inclusive sua relação com a política brasileira. Neste trabalho, pretendo discutir a respeito da atuação de um grupo protestante específico - a igreja batista, em um campo específico - a educação escolar.

De todos os grupos protestantes que se inseriram no Brasil, a igreja batista foi uma das que o fez mais tardiamente - apenas em 1881 foi enviado o primeiro casal de missionários para trabalhar especificamente com os brasileiros (PEREIRA, 1979). Os batistas eram um grupo minoritário nos Estados Unidos (AZEVEDO, 1996), e essa posição reflete-se diretamente na obra missionária realizada pela denominação no Brasil. Diferente dos presbiterianos descritos por Nascimento (2007) e Chamon (2005), ou dos metodistas de Mesquida (1994), não encontrei qualquer indício de apoio governamental brasileiro às instituições educativas batistas. Seus colégios, em grande parte, foram criados pela iniciativa de missionários que aqui se instalaram em parceria com brasileiros (MESQUITA, 1940). O recebimento de recursos da Junta de Richmond ${ }^{1}$ para manutenção das instituições escolares era tardio, sendo necessário nos primeiros anos o financiamento da instituição através do pagamento de mensalidades pelos alunos, ou da contribuição de algum benfeitor (SILVA, 2004).

A inserção da obra batista em Minas Gerais não se deu na fase inicial de implantação da denominação no Brasil. Os missionários preferiam as grandes cidades, como Rio de Janeiro, São Paulo, Salvador e Recife. O investimento realizado na região Nordeste foi mais acentuado, se comparado com as demais regiões brasileiras (HARRISON, 1987). Não encontrei, até o momento, qualquer indício da razão que tenha levado os batistas a postergarem a inserção de seu trabalho neste estado. Os missionários que aqui se instalaram, em sua totalidade, vinham de outros trabalhos da denominação no Brasil, e boa parte deles possuía escolarização inferior à dos missionários enviados especificamente para trabalhar nos colégios carioca e pernambucano. Seu trabalho caracterizava-se pelas constantes tentativas de tornar

\footnotetext{
${ }^{1}$ Organização americana batista com atuação missionária em diversas partes do mundo. Foi a responsável pelo envio dos missionários batistas para o Brasil. Maiores informações em Mead (1936) e Oliveira (2011).
} 
autossustentáveis as igrejas que fundavam². Estes fatores podem ser considerados indícios de que sua mudança para este estado estava relacionada à busca por novos campos, em que pudessem realizar seu trabalho ministerial sem um controle tão rígido por parte da Junta de Richmond - ou talvez até mesmo de que esses homens e mulheres não eram considerados a figura ideal do missionário educador para a Junta, levando-os a buscar um campo considerado menos importante, mas no qual pudessem trabalhar livremente.

A difusão da mensagem batista em Minas Gerais foi feita por diversos meios. Igrejas e pontos de pregação foram criados, através de viagens realizadas pelos missionários - quase sempre se guiando pela malha ferroviária disponível. Um periódico foi criado para fazer com que os princípios da denominação e notícias relacionadas à obra missionária chegassem a todas as famílias de convertidos no estado, mesmo quando não havia algum pastor ou missionário disponível para viajar até a cidade. E uma instituição escolar foi criada, em Belo Horizonte, para difundir os ideais da denominação para a nova geração.

Criada em 1918, a Escola Baptista de Belo Horizonte assemelhava-se a uma escola isolada, funcionando em uma classe única na Primeira Igreja Batista da capital. Em 1920 transformou-se em Collegio Baptista Americano Mineiro (CBAM). Em 1921, após a compra de seu prédio próprio com recursos enviados pela Junta de Richmond, o Collegio passou a funcionar com uma configuração apropriada para seu nome: classes seriadas que se estendiam do jardim de infância ao magistério para as moças ou seminário teológico para os rapazes, internato, e cursos diversificados, como, por exemplo, idiomas, música e artes (50 ANOS, 1968). Esta transformação tornou o CBAM uma instituição referência para os batistas mineiros, recebendo internos de diversas cidades do interior do estado, além dos externos belo-horizontinos.

Neste artigo, pretendo demonstrar as representações construídas pelos missionários a respeito das famílias brasileiras, durante a década de 1920. Tomarei o conceito de representações advindo do campo historiográfico, conforme definido por

\footnotetext{
${ }^{2}$ O periódico da denominação no estado, O Baptista Mineiro, retrata em diversos números o que era chamado pelos missionários de A Grande Campanha Baptista. Esta consistia em tornar as igrejas autossustentáveis através da prática do dízimo por seus fiéis. Em boa parte do Brasil, as igrejas batistas só se tornaram independentes financeiramente dos Estados Unidos na década de 1980 (O Jornal Batista Edição do Centenário, 1982).
} 
Chartier (1990). Para o autor, este conceito refere-se à forma como as realidades sociais são percebidas e interpretadas, considerando que esta leitura nunca é dotada de neutralidade. Para que a interpretação de um grupo prevaleça, outra tem de ser menosprezada. Através dessa prática, "a realidade é contraditoriamente construída pelos diferentes grupos" (p. 23). Esta construção possibilita a criação de identidades sociais, que "marcam de forma visível e perpetuada a existência do grupo, da classe ou da comunidade" (idem). Investigando a maneira como os missionários representavam as famílias nos materiais de divulgação da instituição escolar batista, podemos compreender sua visão dos brasileiros, e também o que atraía e convencia os pais a ali matricularem seus filhos. O CBAM só se tornou atraente para essas famílias porque ia ao encontro das expectativas de uma parcela da sociedade da época para a escolarização de seus filhos. Buffa (2002, p. 26) afirma que "na história das instituições escolares aninha-se, de fato, a filosofia educacional da sociedade que as cria e mantém". Embora este trabalho trate de um colégio específico e de um grupo reduzido de famílias, é possível que sua história nos ajude a compreender as expectativas da sociedade da época acerca da escolarização de suas crianças.

Para alcançar estes objetivos, recorrerei às informações contidas nos prospectos de propaganda do CBAM e em algumas matérias do periódico denominacional, O Baptista Mineiro. Estas fontes provêm de um acervo pouquíssimo explorado, o Centro de Memória do Colégio Batista Mineiro. Lá, encontra-se o arquivo morto da instituição, bem como publicações antigas referentes à instituição, recortes de jornal, mobiliário escolar e materiais didáticos. De acordo com Rosa Souza (2000, p. 13), “os arquivos escolares oferecem fontes valiosas para o estudo histórico das instituições educativas e da cultura escolar, que permitem reconstituir a identidade e a trajetória de vida de um determinado estabelecimento de ensino". Através dos arquivos escolares, podemos encontrar elementos que permitem a reflexão acerca do passado da instituição, dos sujeitos que a frequentaram, das práticas ali produzidas e de sua relação com a cidade (Diana VIDAL, 2005). Além do mais, para Gatti Junior (2002, p. 4), o "arsenal de fontes e informações fundamentais presentes nos arquivos escolares permite a construção de interpretações sobre elas próprias e, sobretudo, sobre a história da educação brasileira." 


\section{O ambiente da educação}

Para discorrer acerca do ambiente considerado adequado pelos batistas para a educação das crianças, recorrerei a um trecho de um discurso proferido pelo missionário americano A. B. Christie, na ocasião da reunião da Convenção Baptista Mineira de 1923. Este homem não era missionário em Minas Gerais, mas foi convidado a proferir uma palestra sobre educação na referida reunião, que tinha um caráter formativo para os pastores e missionários da denominação que atuavam neste estado. Além dos ministros, estavam presentes na reunião uma elite eclesiástica, composta pelos membros escolhidos em eleição para representar suas igrejas na ocasião. Esta escolha muitas vezes estava diretamente relacionada com a ocupação do cargo de diácono por parte do membro, ou de sua disponibilidade financeira para arcar com os custos da viagem e estadia. A importância do conteúdo deste discurso aos olhos da liderança batista era tamanha, que sua transcrição foi publicada na primeira e segunda páginas de O Baptista Mineiro no mesmo mês em que a reunião ocorreu. A publicação deste discurso o tornava acessível a todas as famílias batistas mineiras, aumentando assim sua influência. Vejamos, portanto, um trecho deste texto:

O fator principal na educação é o ambiente. Cada experiencia deixa uma impressão no educando. A impressão póde ser boa ou má. Os costumes, habitos e linguagem são geralmente determinados pelos paes e companheiros. É difficil para uma creança subir acima do seu ambiente. No ambiente o factor mais importante è a personalidade. (...)

A educação baptista procura tirar a creança do mundo de mal, das influencias viciosas, para ter a oportunidade de formar seu caracter, rodeada pelas melhores influencias possíveis. Ella procura formar nos seus alunos um corpo são, um intelecto instruído, uma moral pura, preparando-os para exercerem uma influencia que ennobreça o trabalho manual, eleve a sociedade, purifique a politica, tornando o mundo um logar possivel para a mocidade viver e crescer sem tantos perigos e tentações. (O BAPTISTA MINEIRO, jan/1923, p. 1-2)

Christie demonstra certa preocupação com o ambiente em que o educando viveria, e os hábitos que ele ali poderia aprender. A importância da experiência na aprendizagem é uma característica fundamental da educação frobeliana, adotada pelos 
colégios batistas nesse momento. Neste trecho, Christie ressalta que seria necessário tirar a criança do mundo de mal, para assim proporcionar as experiências consideradas adequadas para a formação da criança. Considerando que o CBAM funcionava prioritariamente em regime de internato, podemos pensar que a família brasileira era considerada um ambiente inadequado para a educação das novas gerações. Ali inserida, a criança jamais ultrapassaria os limites do brasileiro. Seria necessário inseri-la em um ambiente controlado pelos missionários americanos, onde ela aprenderia comportamentos civilizados, capazes de trazer o almejado progresso para a sociedade que, de acordo com o discurso de Christie, se expressaria no trabalho, na moral e na política.

Embora o CBAM funcionasse em regime de internato, recebia também alunos externos - contanto que suas famílias residissem em Belo Horizonte. O horário de aulas, porém, se estendia durante todo o dia, fazendo com que os externos passassem mais tempo na instituição do que em suas próprias casas, em companhia de suas famílias, amigos e vizinhos. É notório que os prospectos de propaganda da instituição enfatizavam sempre a matrícula para alunos internos. É possível que isso se deva ao alcance desta literatura: uma família vizinha da instituição não necessitaria de propagandas por correspondência para conhecê-la, bastava uma visita. Mas não devemos desconsiderar que era interessante, para o CBAM, que houvesse o máximo possível de alunos internos, maximizando o êxito de sua função educadora. Retirando os alunos de seus lares e suas famílias, seria possível ensinar-lhes a conviver em um ambiente diferente do que estavam acostumados, inculcando-lhes novos princípios, novas atitudes, novas posturas e uma nova religião.

Considerar o ambiente familiar inadequado e a família incapacitada para educação das crianças é uma tendência que aparece expressa em outros trabalhos sobre educação escolar em um recorte temporal próximo ao estudado. Esta tendência aparece tanto em instituições laicas quanto confessionais, tanto em internatos quanto em externatos. Lage (2006) descreve as atividades de um colégio interno confessional feminino católico no interior mineiro, no período compreendido entre o final do século XIX e início do XX. A autora destaca o cuidado por parte da direção para que as meninas tivessem o mínimo de contato possível com suas famílias. Na concepção das freiras que dirigiam a instituição, 
ali as alunas poderiam receber uma educação completa, que as preparasse para ser boas esposas e mães na sociedade moderna. Junto a suas famílias e em seus lares, as meninas e jovens estariam sujeitas às distrações e entretenimentos do lar, inviabilizando a completude da educação moral. Acerca das relações entre família e escola, Faria Filho (2000) discorre sobre como o assunto era tratado na Revista do Ensino entre 1925 e 1930. O autor afirma que neste periódico a ação da família é retratada como "uma ação complementar à da escola e a ela subordinada, porque se desconfia da competência da família para bem educar; na verdade, no mais das vezes, afirma-se que a família não consegue mais educar seus filhos" (p. 46). Os professores deveriam ser o modelo de vida social seguido pelos alunos, afim de que estes se tornassem cidadãos dignos e úteis. Para que a família pudesse auxiliar a escola nesse projeto, tornava-se necessária a educação dos pais em conformidade com os objetivos propostos. O aluno serviria de intermediário nesse processo, levando até sua família o conhecimento adquirido na escola. Magaldi (2003, p. 17) afirma que, dentre os escolanovistas, "foram muitos os intelectuais que se mobilizaram em ações educativas destinadas às famílias e defenderam a ação do Estado e da escola nessa mesma direção." O principal objetivo dessas ações seria capacitar a família a realizar um trabalho complementar em relação à escola.

Retornando ao objeto deste capítulo, percebe-se, a partir das fontes consultadas, que o relacionamento entre o CBAM, as famílias e os alunos parece ser o de entrega quase total dos últimos aos cuidados e princípios da instituição. O diretor assumia o posto de principal veículo de comunicação nesse relacionamento. Ele se tornaria, para os alunos, uma representação da família ausente. Ele ainda seria uma representação das regras, anseios e exigências da escola, tanto aos olhos das famílias como dos alunos.

$\mathrm{Na}$ relação com os alunos, o diretor buscava estabelecer um relacionamento o mais familiar possível. O PROSPECTO (1924) traz a seguinte afirmação: “A vida nestes internatos é muito familiar. Luctamos para desenvolver os nossos internos socialmente, exigindo que cada um cumpra seus deveres" (s.p.). Já a edição de 1927 afirma que "Relações familiares são mantidas com os alumnos da melhor forma possível. A disciplina é enérgica, porém paternal, com o intuito de desenvolver a ordem na vida educativa do alumno." (PROSPECTO, 1927, s.p.) Colaborava à manutenção de um ambiente familiar o fato de os diretores dos internatos masculino e feminino e suas famílias residirem no 
próprio internato. Assim, nos internatos, família e alunos se misturavam, posto que o sr. e a sra. Morgan, diretores do internato masculino, eram envolvidos no trabalho da Escola, e sua filha também era aluna da instituição. O mesmo também acontecia com a família Allen, cujos pais eram diretores do internato feminino.

O diretor deveria ser uma pessoa bem próxima dos alunos. No PROSPECTO (1921; 1924; 1927) encontramos o seguinte parágrafo: “O director em certas horas marcadas receberá, no seu gabinete, qualquer alumno que o procure para consultal-o sobre o estudo ou qualquer outro assumpto, pois é com o maximo prazer que elle serve aos seus alumnos de conselheiro e amigo" (s.p.). Segundo memória do pastor Astrogildo Malheiros, aluno da Escola entre 1924 e 1928, a convivência muito familiar trazia, às vezes, dificuldades na disciplina: "Dado o convívio familiar, alguns alunos facilitando, de quando em vez abusavam da disciplina; e com isto traziam, às vezes, alguma reação da parte do Vice Diretor (Dr. Allen), que com sua capacidade e aptidão, soube sempre manter a ordem" (50 ANOS, p. 25). A pessoa do diretor tornava-se um referencial e um exemplo para os alunos, na ausência da família. Pastor Astrogildo, ao escrever sua memória, relata quanto às práticas esportivas que "em todos os esportes e brincadeiras, o Diretor muito estimulava os alunos; identificando-se mesmo muitas vêzes com êles." Recaía sobre o diretor também a responsabilidade acerca do desempenho escolar dos alunos, conforme os Prospectos de 1924 e 1927: “Os membros do corpo docente, vendo que um estudante não está fazendo progresso nos estudos ou procedendo mal, deverão informar o director, que resolverá o caso."

Como se pode perceber nos parágrafos acima, os alunos matriculados no CBAM aprenderiam mais do que conteúdos escolares: eles seriam socializados para a convivência em uma família americana e batista. Através do exemplo do diretor e de sua esposa, os alunos e alunas aprenderiam a ser esposo e esposa, pai e mãe no futuro. Aprenderiam as formas de relacionamento e tratamento doméstico, a hierarquia familiar, a divisão de tarefas, a ludicidade no tratamento com os filhos, a responsabilidade no tocante à educação, a prática religiosa doméstica, a administração do tempo, os costumes alimentares ${ }^{3}$, e tudo o mais que envolve a vida privada e familiar. Mais do que

\footnotetext{
3 Embora os prospectos do CBAM nada descrevam acerca da alimentação recebida pelos internos, é provável que fosse a mesma recebida pelo diretor e família, posto que residiam no mesmo domicílio. Além
} 
uma educação moral escolarizada, conforme descreve Lage (2006) em seu trabalho, os alunos do CBAM eram conformados ao modelo familiar difundido pela denominação através da convivência quotidiana e prática. E, da mesma maneira que descreve Faria Filho (2000), quando esses alunos retornassem a suas famílias, teriam a oportunidade de educar seus pais de acordo com os princípios aprendidos no internato. Assim como os escolanovistas defendiam a formação da família pelo Estado e pela escola (Magaldi, 2003), a denominação investia na formação das famílias batistas através de outras estratégias educativas, tais como as práticas eclesiásticas, a música e a difusão do periódico O Baptista Mineiro. Com a influência dos alunos e das estratégias citadas acima, os batistas esperavam operar a transformação social tão almejada, a partir do presente e em direção ao futuro.

\section{A incapacidade das famílias brasileiras}

Através das representações construídas nos prospectos, percebe-se a desconfiança, por parte da direção do CBAM, em relação às famílias dos alunos. Matricular um filho na instituição significava submeter, a criança e a família, à autoridade e disciplina representadas na pessoa do diretor. Mesmo nos momentos de folga dos alunos, a autoridade do diretor é representada em paridade com a autoridade familiar, conforme podemos ver no exemplo abaixo:

Os alumnos internos poderão sahir aos sabbados, desde que sejam acompanhados por seus paes ou pessoas por elles encarregadas, mediante o consentimento expresso do director. O número de vezes, porém, de sahidas será limitado a uma vez por mez, podendo o alumno gozar maior numero de vezes de sahidas, desde que tenha bom procedimento e medias optimas. Também receberão visitas autorizadas pelos paes durante o período de recreio. (PROSPECTO, 1927, s.p.)

disso, essa prática seria coerente com a americanização dos modos de vida, conforme acontecia na instituição. Tomando exemplo de outra instituição em recorte temporal próximo, alunos internos e direção receberem a mesma alimentação é apontado como uma das vantagens da matrícula no Collegio Dom Viçoso, em uma de suas publicidades (JORNAL DE MINAS, 11/07/1918). Por outro lado, encontramos em OBM (set/1921) um apelo para contribuições à instituição em forma de arroz e feijão - alimentos tipicamente brasileiros. Assim, é possível que os americanos tenham se acostumado com os alimentos brasileiros, mas as práticas relacionadas à refeição - horários, rituais, etc - tenham sido impostas aos alunos do CBAM. 
Não bastava o consentimento familiar; era necessário também o consentimento do diretor. O rendimento escolar também manifesta esse princípio. O CBAM se comunicava com a família a esse respeito através de boletins: enviava-se o rendimento do aluno à família, que deveria manifestar ao diretor sua ciência acerca da situação escolar da criança:

Boletins mensaes são enviados aos paes mostrando as notas nas matérias, a applicação, comportamento e freqüência do alumno. Taes boletins devem ser assignados pelos Paes e devolvidos ao director da instituição. Assim, os Paes podem desde logo apreciar o estimulo que advem de tal systema. (PROSPECTO, 1924, s.p.)

Em determinadas situações, o Colégio representava-se como maior interessado no bem do aluno, fazendo com que até mesmo os pais lhe devessem explicações: “...A ausência terá de ser justificada perante o director, mediante uma explicação escripta pelos paes. É de summa importância que os paes não sanccionem desculpas, a não ser que sejam bem justificadas" (PROSPECTO, 1924, s.p.). Nesse caso, a Escola representa-se como guardiã do direito e dever dos alunos de aprender, ao passo que representa a família como passível de criar situações para que a criança não usufrua de sua condição de aprendizado.

Embora estas práticas diminuam - ou até mesmo anulem - a autoridade da família sobre seus filhos, não podemos esquecer que se situam em um contexto escolar em que a família é comumente representada como inabilitada para oferecer uma educação de qualidade e promover a utilidade social de seus filhos no futuro. Além do mais, tratava-se de uma instituição escolar americana e confessional - três características que lhe “conferiam autoridade”. Por ser escolar e seriada, poderia oferecer a educação considerada adequada às crianças da modernidade republicana. Por ser americana, tinha condições de oferecer uma transformação de vida a seus alunos. Os pais que ali matriculavam seus filhos certamente tinham a esperança de transformá-los em cidadãos conformes ao modelo em que o Brasil, à época, se espelhava (cf. WARDE, 2000). Assim, não importava às famílias a perda de parte de sua autoridade: importava a elas que, no futuro, seus filhos pudessem ser contemplados pelos demais brasileiros como um 
espelho de civilidade e progresso. Por ser confessional, o CBAM oferecia às famílias batistas uma educação com princípios considerados pelo grupo como divinos. O próprio liberalismo e democracia, ensinados na instituição como princípios civis, vestem-se teologicamente na prática da denominação (cf. TAYLOR, 1941; BEZERRA, 1960). Assim, cada elemento da educação secular seria interpretado, pelos membros do grupo, com um viés religioso. Não podemos nos esquecer da possibilidade de que muitas famílias batistas mineiras enxergassem a mudança de religião por que passaram não como uma experiência relacionada ao contato com o numinoso (OTTO, 1985), mas como uma transformação de seu modo de vida seguindo o modelo do missionário, americano e civilizado. É provável que algumas famílias tenham enviado seus filhos para aprender os modos americanizados através da convivência no internato, acreditando assim torná-los, além de bons cidadãos, verdadeiros servos de Deus.

\section{Contribuição financeira}

Por maior que fosse representada a autoridade e a capacidade da Escola, em um aspecto ela era representada como dependente do apoio das famílias para conseguir levar adiante seus propósitos: o financiamento. Podemos observar, a partir de uma matéria de O Batista Mineiro, publicada em setembro de 1921, o seguinte apelo às famílias batistas: "Tambem é para desejar que os irmãos enviem para o collegio generos de primeira necessidade, como arroz, feijão, etc., afim de diminuir as nossas despesas" (p. 2). E ainda:

Nos Estados Unidos, durante a guerra, todos os cidadãos, millionarios e pobres resolveram reduzir a ração diaria para servir os que lutavam com a fome em outros paizes. Este é um exemplo de um povo guiado pelos idéaes christãos que devemos imitar, um pouco de economia, com menos apêgo ás moedas, poderemos levar a instrucção a muitas crianças e resgatar do erro e da infelicidade presente e eterna almas pelas quaes Jesus morreu, dando-nos o exemplo supremo de abnegação. Irmãos, verdadeiramente somos christãos só de nome, se não temos o elevado espirito de sacrificio pelas causas nobres.

A educação baptista em Minas está requerendo a nossa completa consagração.

Que iremos fazer? (p. 3) 
A contribuição financeira pessoal para propósitos previamente determinados é apontada, no texto, como um exemplo americano que deveria ser seguido pelos brasileiros. É interessante a comparação realizada: enquanto os americanos auxiliaram os que lutaram contra a falta de alimento, os brasileiros deveriam auxiliar aqueles que lutavam contra a falta de conhecimento, possibilitando, através de suas doações, o aumento do número de matrículas no CBAM. Da mesma maneira que não é possível que alguém sobreviva sem se alimentar, a falta da instrução considerada adequada poderia levar as crianças a uma vida que não era considerada digna, e à condenação eterna de sua alma, castigo máximo para o grupo. Isso poderia ser evitado se o brasileiro - claramente representado como esbanjador e apegado ao dinheiro - abrisse mão de suas moedas para contribuir à manutenção do CBAM, possibilitando seu funcionamento e até mesmo a abertura de novas vagas através de bolsa de estudos ${ }^{4}$. Também cabe observarmos a representação que é feita do povo de ambos os países envolvidos neste trecho: enquanto os americanos tinham um problema sério - a guerra - e nem por isso deixaram de contribuir financeiramente, o brasileiro tinha por principal problema a sua própria conduta, sua inabilidade em administrar seu próprio dinheiro. Para que o brasileiro resolvesse seus problemas, seria necessário tão-somente imitar o americano.

Outro aspecto que gostaria de ressaltar nesse trecho diz respeito aos aspectos propriamente religiosos e místicos nele contidos. Recorro, para isso, ao conceito de numinoso, conforme definido por Rudolf Otto (1985). Para o autor, o contato místico com o sagrado - numinoso - produz no homem a percepção de sua pequenez, chamada pelo autor de sentimento do estado de criatura (p. 17), em comparação à majestas (p. 29), sentimento de preponderância absoluta do numinoso sobre todas as coisas, de seu poderio. O numinoso também produz no homem um estado de um terror místico, que se constitui o pânico perante seus aspectos de bondade e terribilidade. Esta experiência, de acordo com o autor, leva o homem a experimentar uma energia à qual "se referem as expressões simbólicas de vida, de paixão, de sensibilidade, de vontade, de força, de

\footnotetext{
${ }^{4}$ As contribuições enviadas pelos fiéis batistas possibilitaram a criação do que era chamado de Fundo Auxiliador. Esta organização tinha o objetivo de conceder bolsas de estudo a alunos cujas famílias não tinham condições de mantê-los na instituição (50 ANOS, 1968).
} 
movimento, de excitação, de actividade, de impulso" (p. 34). A experiência com o numinoso leva o homem à atitude, e não simplesmente a uma paralização aterrorizada.

Dentre o protestantismo de missão brasileiro, usualmente os Estados Unidos são representados como portadores da manifestação do majestas perante os brasileiros. Essa representação faz parte da concepção de destino manifesto (Mesquida, 1994; Karnal, 1996) assumida pelos americanos. No trecho analisado, a majestas é representada pelos idéaes christãos que, de acordo com o autor guiam os Estados Unidos em suas práticas. Assim, a abnegação, representada no texto pela postura dos norte-americanos e pela morte de Jesus em favor das almas, seria uma manifestação da majestas do numinoso. Esta manifestação levaria os brasileiros a perceber sua pequenez, representada através de seus parcos recursos financeiros - moedas, e também na sua forma ignóbil de administrá-los. Perante estas manifestações do numinoso, o brasileiro teria a oportunidade de contemplar e se aterrorizar com toda a bondade manifesta na majestas - sobretudo no tocante à morte vicária de Jesus e sua função na doutrina protestante da graça. Mas se aterrorizaria também com a possibilidade da infelicidade eterna, faceta de terribilidade do poder absoluto, que alcançaria aqueles que não recebessem uma educação considerada adequada. Então, toda a energia produzida no indivíduo que vivenciou este contato com o numinoso seria direcionada para a completa consagração, o envolvimento com aquilo que era requerido - nesse caso, a doação financeira em prol da escolarização batista. Deixar de colaborar poderia ser interpretado como a ausência de contato com a manifestação do numinoso, ou seja, a ausência do elemento místico na adoção da religião. Aqueles que estivessem nessa situação, de acordo com o texto, poderiam ser considerados christãos só de nome.

Podemos assim perceber que a manutenção financeira do CBAM era considerada uma responsabilidade das famílias batistas, independente de terem ou não filhos ali matriculados. O que lhes levaria a contribuir seria a sua necessidade de assemelhar-se cada vez mais com os americanos, e também a sua experiência mística religiosa (ou a necessidade de declarar publicamente ter tido uma). Dessa maneira, todos os batistas eram considerados responsáveis por ajudar a manter um dos principais meios de difusão de sua doutrina em Minas Gerais. 


\section{Considerações finais}

Como ponderado nos itens anteriores, o CBAM foi criado em um contexto em que os Estados Unidos e os americanos eram considerados um modelo a ser imitado pelo Brasil e pelos brasileiros. Assim sendo, a construção de representações negativas acerca de nosso povo e de nossas famílias ajudava a torná-lo uma instituição ainda mais atraente aos olhos das famílias que procuravam a ascensão social de seus filhos através da escolarização. As escolas protestantes, que de acordo com Hilsdorf (2007) eram consideradas modernas por excelência, propunham uma educação liberal, que buscava o desenvolvimento das habilidades do indivíduo. Ainda que enviar os filhos para o CBAM significasse perder parte significativa da autoridade sobre eles, e do controle sobre sua educação, havia famílias que acreditavam ser essa uma opção adequada, posto que seus filhos se tornariam adultos civilizados.

Por outro lado, não podemos ignorar o aspecto religioso da instituição. Enviar o filho para estudar em uma instituição confessional implica que ele receba formação religiosa. Muitas famílias podem ter considerado o ambiente em que viviam, inapropriado para a educação de seus filhos devido às constantes intervenções de outros grupos religiosos, seja através do tradicional sincretismo brasileiro, ou seja, pelas discriminações e sanções sociais constantemente sofridas pelos protestantes no Brasil durante a Primeira República, conforme descritas por Oliveira (1999). Também é provável que algumas famílias tenham enviado seus filhos para ali estudar justamente para que, no futuro, se tornassem o espelho do ideal americano representado nos casais missionários: os rapazes se tornando pastores, as moças se tornando professoras.

Por fim, é necessário considerar o senso de reponsabilidade desenvolvido nos membros brasileiros da denominação acerca da manutenção financeira do CBAM. Embora não tenha contado com um rico benfeitor brasileiro, como foi o caso da instituição escolar batista baiana, todos os membros e igrejas eram considerados responsáveis pela instituição. A educação dos pequenos brasileiros era apontada como uma causa de interesse coletivo, e não apenas familiar ou individual. Através de argumentos sociais ou religiosos - ambos fortemente americanizadores -, os fiéis eram conclamados a contribuir com um dos mais importantes meios de difusão da mensagem 
da denominação no estado. E assim, permitiam que alunos cujas famílias jamais teriam condições de enviá-los para lá recebessem bolsas de estudo, e tivessem acesso à possibilidade de ascensão social por meio da educação escolar civilizadora e americanista. Talvez essa visão do CBAM como uma instituição de interesse e responsabilidade coletiva tenha colaborado ao destino da instituição, que se tornou uma referência no trabalho educacional batista para todo o Brasil (cf. O JORNAL BATISTA - EDIÇÃO DO CENTENÁRIO, 1982) e, atualmente, conta com 96 anos de trabalho ininterrupto.

\section{Referências}

50 ANOS: 1918-1968. Belo Horizonte: CMCBM, 1968.

COLLEGIO D. VIÇOSO. Jornal de Minas. Belo Horizonte: APM, ano I, n. 8, p.3, 11 de julho de 1918.

O Baptista Mineiro. 1920 a 1928. Belo Horizonte.

O Jornal Batista - Edição do Centenário. 15 de outubro de 1982.

PROSPECTO. Belo Horizonte: Collegio Baptista Americano Mineiro, 1921. Mimeografado.

PROSPECTO. Belo Horizonte: Collegio Baptista Americano Mineiro, 1924. Mimeografado.

PROSPECTO. Belo Horizonte: Collegio Baptista Americano Mineiro, 1927. Mimeografado. 
ADAMOVICZ, Anna Lúcia Collyer. Imprensa protestante na Primeira República: evangelismo, informação e produção cultural. O Jornal Batista (1901-1922). 432 f, 2008. Tese (Doutorado em História) - Universidade de São Paulo.

AZEVEDO, Israel Belo de. A celebração do individuo: a formação do pensamento batista brasileiro. Piracicaba: Ed. UNIMEP; São Paulo: Exodus, 1996.

BASTIAN, Jean-Pierre. Protestantismos y modernidade latinoamericana: historia de unas minorias religiosas activas em América Latina. México, D.F.: Fondo de Cultura Económica, 1994.

BEZERRA, Benilton C. Interpretação panorâmica dos batistas. Rio de Janeiro: Casa Publicadora Baptista, 1960 (escrito em Recife).

BUFFA, Ester. História e filosofia das instituições escolares. In: ARAÚJO, J.C.S; GATTI JÚNIOR, D. (Orgs.) Novos temas em História da Educação Brasileira: instituições escolares e educação pela imprensa. Campinas/Uberlândia: Autores Associados/Edufu, 2002.

CHAMON, Carla Simone. Maria Guilhermina Loureiro de Andrade: a trajetória profissional de uma educadora (1896/1913). 2005, 338 f. Tese (Doutorado em Educação) Universidade Federal de Minas Gerais. Belo Horizonte, 2005.

CHARTIER, Roger. A história cultural: entre práticas e representações. Rio de Janeiro: Bertrand Brasil, 1990.

FARIA FILHO, Luciano Mendes de. Para entender a relação escola-família: uma contribuição da história da educação. São Paulo em Perspectiva, São Paulo, v. 14, n. 2, p. 44-50, abr./jun. 2000.

GATTI JÚNIOR, Décio. A história das instituições educacionais: inovações paradigmáticas. In: ARAÚJO, J.C.S; GATTI JÚNIOR, D. (Orgs.) Novos temas em História da Educação Brasileira: instituições escolares e educação pela imprensa. Campinas/Uberlândia: Autores Associados/Edufu, 2002.

KARNAL, Leonardo. Estados Unidos: da colônia à independência. 3. ed. São Paulo: Contexto, 1996.

LAGE, Ana Cristina Pereira. Escolas confessionais femininas na segunda metade do século XIX e início do XX: um estudo acerca do Colégio Nossa Senhora de Sion em Campanha (MG). In: LOMBARDI, José Claudinei; SAVIANI, Dermeval; NASCIMENTO, Maria Isabel Moura do (Orgs.). Navegando pela história da educação. Campinas: HISTEDBR, 2006. Disponível em:

http://www.histedbr.fae.unicamp.br/navegando/artigos_pdf/Ana_Cristina_P_Lage_Artigo .pdf. Acesso em 05 de julho de 2012. 
HARRISON, Helen Bagby. Os Bagby do Brasil: uma contribuição para o estudo dos primórdios batistas em terras brasileiras. Rio de Janeiro: Junta de Educação Religiosa e Publicações, 1987.

HILSDORF, Maria Lucia Spedo. História da educação brasileira: leituras. São Paulo: Thomson Learning, 2007.

MAGALDI, Ana Maria Bandeira de Mello. A quem cabe educar? Notas sobre as relações entre a esfera pública e a privada nos debates educacionais dos anos de 1920-1930.

Revista Brasileira de História da Educação. Campinas: Editora Autores Associados, n. 5, p. 213-231. jan./jun. 2003.

MEAD, Frank S. The Baptists. Nashville, Tennessee: Broadman Press, 1936.

MEDEIROS, Pedro Henrique Cavalcante de. A inserção do protestantismo no Brasil no século XIX: uma breve análise de duas teorias. In: AMARAL, Clínio; BARROS, José D’Assunção; BERRIEL, Marcelo; CALDAS, Marcos; COSER, Miriam; LOBIANCO, Luis Eduardo; SANCOVSKY, Renata Rosental; SILVA, Rosana Marins dos Santos (Orgs.). Representações Poder e Práticas Discursivas. Rio de Janeiro: UFRJ, 2010. (Cd-rom)

MENDONÇA, Antônio Gouvêa; VELASQUES FILHO, Prócoro. Introdução ao protestantismo no Brasil. 2. ed. São Paulo: Loyola, 2002.

MESQUIDA, Peri. Hegemonia norte-americana e educação protestante no Brasil: um estudo de caso. Juiz de Fora/São Bernardo do Campo: EDUFJF/Editeo, 1994.

MESQUITA, Antônio Neves de. História dos Batistas do Brasil: 1907 até 1935. Rio de Janeiro: Casa Publicadora Batista, 1940.

NASCIMENTO, Ester Fraga Vilas-Bôas Carvalho do. Educar, curar, salvar: uma ilha de civilização no Brasil tropical. Maceió: EDUFAL, 2007.

OLIVEIRA, Zaqueu Moreira de. Perseguidos, mas não desamparados: 90 anos de perseguição religiosa contra os Batistas Brasileiros (1880 - 1970). Rio de Janeiro: Juerp, 1999.

OLIVEIRA, Zaqueu Moreira de. Um povo chamado batista: história e princípios. Recife: Kairós, 2011.

OTTO, Rudolf. O sagrado: um estudo do elemento não-racional na idéia do divino e a sua relação com o racional. São Bernardo do Campo: Imprensa Metodista, 1985.

PEREIRA, José dos Reis. Breve história dos batistas. 2. ed. Rio de Janeiro: Junta de Educação Religiosa e Publicações, 1979.

RIBEIRO, Boanerges. Protestantismo no Brasil Monárquico, 1822-1888: aspectos culturais de aceitação do protestantismo no Brasil. São Paulo: Pioneira, 1980. 
SILVA, Cleni da. Educação Batista: análise histórica de sua implantação no Brasil e de seus desafios no contexto atual. Rio de Janeiro: JUERP, 2004.

SOUZA, Rosa Fátima de. Um itinerário de pesquisa sobre a cultura escolar. In: CUNHA, Marcos Vinicus da (Org.). Ideário e imagens da educação escolar. São Paulo: Autores Associados, 2000. p. 3-28.

TAYLOR, William Carey. Manual das Igrejas. Rio de Janeiro: Casa Publicadora Batista, 1941.

VIDAL, Diana Gonçalves. Cultura e prática escolares: uma reflexão sobre documentos e arquivos escolares. In: SOUZA, Rosa Fátima de; VALDEMARIN, Vera Teresa. A cultura escolar em debate: questões conceituais, metodológicas e desafios para a pesquisa. São Paulo: Autores Associados, 2005. p. 3-30.

VIEIRA, David Gueiros. Liberalismo, masonería y protestantismo em Brasil, siglo XIX. In: BASTIAN, Jean-Pierre (Org.). Protestantes, liberales y francmasones: sociedades de ideas y modernidade em América Latina, siglo XIX. México, D.F.: Cehila, 1990. p. 39-66.

WARDE, Mirian Jorge. Americanismo e educação: um ensaio no espelho. São Paulo em Perspectiva, v. 14, n. 2, 2000. p. 37-43. 